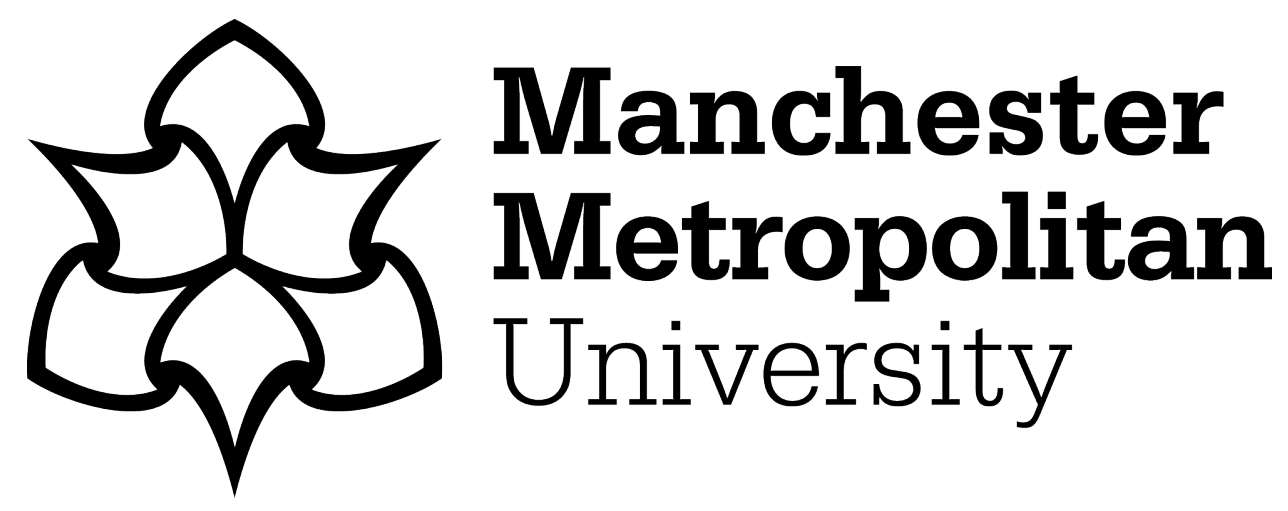

Pike, Joanne, Picking, Richard and Cunningham, Stuart ORCID logoORCID: https://orcid.org/0000-0002-5348-7700 (2021) Robot companion cats for people at home with dementia: a qualitative case study on companotics. Dementia, 20 (4). pp. 1300-1318. ISSN 1471-3012

Downloaded from: https://e-space.mmu.ac.uk/626192/

Version: Accepted Version

Publisher: SAGE Publications

DOI: https://doi.org/10.1177/1471301220932780

Please cite the published version 


\title{
Robot companion cats for people at home with dementia: a qualitative case study on companotics
}

\author{
Joanne Pike, ${ }^{1}$ Richard Picking, ${ }^{2}$ and Stuart Cunningham ${ }^{3}$ \\ ${ }^{1}$ Faculty of Social and Life Sciences \\ Wrexham Glyndŵr University, Mold Road, Wrexham LL11 2AW, Wales, UK. \\ ${ }^{2}$ Faculty of Arts, Science and Technology \\ Wrexham Glyndŵr University, Mold Road, Wrexham LL11 2AW, Wales, UK. \\ ${ }^{3}$ Centre for Advanced Computational Science \\ Manchester Metropolitan University, Manchester M1 5GD, UK.
}

\begin{abstract}
The use of robot companion pets for people in care homes has been extensively studied. The results are largely positive, and suggest that they are valuable in enhancing wellbeing, communication and behavioural aspects. However, there has been little research in people's own homes, possibly due to the cost and complexity of some of the robot pets currently available. As dementia affects people in different ways, this study explores the effects of a robot cat for people in their own homes, without specifically investigating the effects on a particular symptom. We utilised a case study design to investigate the proposition that various factors influence the impact of a robot cat on the person living with dementia and their carer, including acceptability of the robot pet and acceptance of dementia and its symptoms. The qualitative analysis explores the similarities and differences within the data which were gathered during interviews with people with dementia and their families. This analysis revealed four themes: Distraction, Communication, Acceptance and rejection, and Connecting with the cat and connecting with others. These themes were synthesized into two overarching themes: The effect of the cat on mood and behaviour, and The interaction with the cat. We present the acceptability and impact of the robot cat on symptoms of dementia, with data presented across and within the group of participants. Our analysis suggests that benefits of the robot pet were evident, and although this was a small-scale study, where they were accepted, robot pets provided positive outcomes for the participants and their families.
\end{abstract}

\section{Keywords}

Companion robots, dementia, pets, at home

\section{Introduction}

The benefits of pet-assisted therapy are well-known (McNicholas et al., 2005; Cherniak \& Cherniak, 2014). In particular, the effects on people with memory impairments are profound; a longitudinal observational study in the USA (Winner, 2014) found that integrating pets in the care home environment created a sense of purpose and life, helping the person engage. A review on the use of animal assisted interventions and their effect on people living with dementia produced evidence that symptoms of dementia can be reduced, whilst social interaction is promoted 
(Bernabei et al., 2013). The study of companotic ${ }^{1}$ animals is also long-established, demonstrating the comfort and improvements in health and wellbeing that they bring to people, in fields as diverse as mental health (Rabbitt, Kazdin, \& Scasellati, 2014), dementia (Moyle et al., 2013), diabetes (Nalin M, Baroni I, Sanna A, Pozzi, 2012), and neurological diseases (Burton, 2013).

Engagement and communication are vital for human wellbeing, and disorders such as dementia often limit the engagement and communication with others. Disorders such as autism also limit social interaction, and several research studies using robots with children living with autism have shown that interaction with them has a positive effect on their interaction with others (Feil-Seifer \& Mataric, 2008; Cho, Kwon \& Shin, 2009; Kim, Lee, Jang \& Ku, 2010; Menghoni et al., 2017). Moyle et al. (2015) found that engagement increased and agitation decreased for people with dementia using the robotic seal PARO. Robot pets have also been found to reduce loneliness in residential care settings (Robinson, Macdonald, Kerse \& Broadbent, 2013), and there are some studies that focus specifically on the role of robot cats in such settings (Libin \& Cohen-Mansfield, 2004; Gustafsson, Svanberg \& Muellersdorf, 2015). The effect of robot pets has been researched in the care home setting often (Kidd, Taggart \& Turkle, 2006; Wada \& Shibata, 2006; Shibata, 2012; Joransen, Pedersen, Rokstad \& Ihlebaek, 2015; Mendes, 2016), but of the 33 studies examined in the scoping review undertaken by Abdi, Al-Hindawi, Ng \& Vizcaychipi (2018), only one study had been undertaken in the home. The study by Tanaka et al. (2012) was the sole study to leave the robot in the home for a period of time, although this was a humanoid robot rather than a robot pet. The remaining 32 studies reported on research undertaken in a care home setting, which involved the utilisation of robot pets as part of therapeutic interventions.

While there are those who question the use of robot pets, concerned that their introduction may lead to less in the way of human interaction (Sparrow \& Sparrow, 2006), the bulk of contemporary research suggests the converse is true, and that the therapeutic use of these robots leads to an increase in social interaction. The study reported upon in the present paper did not include therapy as part of the research, but involved researching the experiences of people living at home with dementia following being given a robot cat. In this way, the impact of the cat could be examined, as no other intervention had been implemented as part of the research study. This paper aims to expand on the previous research which has taken place in shared community spaces (e.g. residential care homes), specifically by concentrating on the effects of robot pets in a home environment, where the person living with dementia lives an independent life, albeit with the support of both family and/or professional carers.

\section{Methodology}

The proposition of our research is that various factors influence the impact of a robot pet on the person with dementia and their carer(s), including acceptability of the cat, and the acceptance of dementia and its symptoms.

\footnotetext{
${ }^{1}$ Companotics: "The research and development of computerized companion devices, especially companion robots" (Picking \& Pike, 2017)
} 
This research comprises a qualitative investigation into the use of robot cats as companion robots for 12 people living at home with family and/or carer support. Some participants had a diagnosis of Alzheimer's Disease, but some were identified by their family as having dementia symptoms, and so had come forward for inclusion in the study even though there was no official diagnosis. Because of the variability in their symptoms, and their specific needs in relation to these, there was the opportunity to bring the results together to form a case study, so that what follows appeals to a multiple case study methodology and, as proposed by Stake (2005), results will be thematically analysed within cases and across cases in cross-case comparison (Chmiliar, 2010) utilising an interpretive approach. Holistic case study design such as this may be used to gather data where the aim is to interpret the experiences of the participants (Yazan, 2015). Themes will therefore be presented from the analysis and assertions about the cases as a whole, or as Stake terms this single entity, the quintain (Stake, 2006). In this way, it is possible to present the data from participants in order to identify the similarities and differences and to consider "the relationship between the phenomenon and its contexts" (Stake, 2005, p. 139). The researchers are seeking, therefore, to tell the story of the data as a whole. As part of the data collection, one short initial interview was undertaken with the participant and their families two weeks after the participant received their cat and another, which tended to be slightly longer, at three months. In order to elicit more detailed information about the nature of the impact of the robot cat, participants and their families were encouraged to take photographs (autophotograpy) to stimulate memories and ease of discussion at interview, as suggested by Glaw, Inder, Kable \& Hazelton (2017). Murray and Nash (2017), note that photographs are able to express complex concepts and provide insight into their social context. Some families seemed to enjoy doing this and they were pleased to share the photographs of the robot cat and of their loved one's interaction with the cat and with them, though not everyone chose to do this. Where a participant or their family had taken a photograph, photo elicitation was used within the second interview, to help the participants discuss the impact of the cat on their lives, and conversation flowed well when the participants presented these photographs during the interviews (see anonymised examples of photographs in Appendix A). The photographs were not separately analysed in this paper.

\section{Methodological Considerations}

This is a small-scale study that seeks to inform and enlighten rather than to discover a 'truth' as might be more the case in a positivist approach (Denzin and Lincoln, 1998). Therefore, an interpretive turn to the data analysis has been taken, supported by verbatim quotes from participants to demonstrate rigour. Interpretation will always be limited by the horizons of the interpreter, or as Heidegger (1962) referred to it, 'situatedness' or 'forestructure of understanding'. The forestructure of understanding presented here is of the participants in their own context. The data is interpreted by a Nursing Academic with knowledge and experience in the field, therefore interpreted through a nursing lens (Peacock, 2001). As such, the reader will be able to judge for themselves the trustworthiness (Lincoln and Guba, 1995) of the results as underpinned by a shared understanding of the context within which the interpretation has taken place and is presented. 


\section{Ethics and enrolment of participants}

Ethical approval for this research was applied for and granted by the Local Ethics Committee of the University. Subsequently, an advertisement was placed in the local media asking people to apply to take part in the study. They could either self-refer or refer their loved ones to take part. Inclusion criteria were that they were considered by themselves or their family to be living with dementia symptoms, that they were living at home and that they were cared for by family, friends and/or carers. There was no stipulation of age or gender but they needed to be fairly local to the geographical area of the University in order that the researchers could visit readily. Where the cat was accepted, it was not removed following the study since the participants may have connected with it (as will be seen below) and it may have been distressing to remove it. This was considered more important than the potential of study bias, due to the cat possibly being regarded as a 'gift'.

Participants were visited by a researcher with clinical knowledge and experience of nursing people living with dementia. A dementia assessment tool was not administered as this research is not of a clinical nature, since the phenomenon of concern here is the interaction with the cat and its effect on behaviour rather than the medical condition itself..

Participants were enrolled to the study if they wished to take part, and if either they or their carers were able to converse with the researcher. All participants were able to give their consent, or their families were able to do so legally on their behalf. Where participants rejected the cat outright at the first meeting with the researcher, the researcher did not return to undertake an interview, since the purpose of this interview was to discuss the impact of the cat.

At the first meeting, following introductions and initial discussion of the research, the researcher demonstrated the cat to the participants and their families and research information sheets were given. With their permission, the researcher then gave the cat to the participant to hold should they wish to, or placed it by their side if that was preferable. Written consent to take part was not taken until all introductions had been made, and participants fully understood the aim of the research. Following this, instructions in use of the cat were given, i.e. how to switch it on and off and where the batteries were inserted, and details left of who to call should there be any concerns or questions.

\section{Profile of the participants}

The age of the participants was not recorded, since the researchers were only interested in the impact of the robot cats for people with dementia. However, all but one of the 12 participants were female and all were above retirement age. Of the four participants whose family told us they did not have a diagnosis, but appeared to have early symptoms of dementia, three were female and one male. These participants all rejected the cat, but each for different reasons. Either they did not like cats, they did not think it would help them, they did not like the robot cat, or were resistant to any interventions. Other than those participants who rejected the cat, three participants were lost to the study, since two died and the other was admitted to hospital, and the 
family did not re-establish contact with the research team subsequent to their admission.

Table 1 displays the participant group profiles.

Table 1. Participant profiles

\begin{tabular}{|c|c|c|l|}
\hline $\begin{array}{c}\text { Participant } \\
\text { No. }\end{array}$ & Gender & $\begin{array}{c}\text { Accept (A) } \\
\text { Reject (R) } \\
\text { Lost to study (L) }\end{array}$ & \multicolumn{1}{|c|}{$\begin{array}{c}\text { Reason for rejection } \\
\text { (paraphrased) }\end{array}$} \\
\hline 1 & M & R & doesn't like cats \\
\hline 2 & F & R & prefers her teddys \\
\hline 3 & F & R & not interested \\
\hline 4 & F & R & resistant to support \\
\hline 5 & F & A & - \\
\hline 6 & F & A & - \\
\hline 7 & F & A & - \\
\hline 8 & F & AL & - \\
\hline 9 & F & L & - \\
\hline 10 & F & A & - \\
\hline 11 & F & A & - \\
\hline 12 & F & L & - \\
\hline
\end{tabular}

In summary, participants 1, 2, 3, and 4 rejected the cat; participants 9 and 12 were lost to the study before they could contribute, due to death; participants 5,6, 7, 10, and 11 contributed fully to the study; and participant 8 contributed to the first interview of the study, but was lost subsequently, due to hospital admission.

Table 2 displays the contributing participants' living circumstances, as well as the key contact(s) who participated in the interviews.

Table 2. Contributing participant circumstances

\begin{tabular}{|c|c|c|c|}
\hline $\begin{array}{c}\text { Participant } \\
\text { No. }\end{array}$ & Living circumstances & $\begin{array}{c}\text { Professional care } \\
\text { support }\end{array}$ & $\begin{array}{c}\text { Key } \\
\text { contact/interviewee(s) }\end{array}$ \\
\hline 5 & Lives with husband & None & Husband \\
\hline 6 & $\begin{array}{c}\text { Lives in sheltered } \\
\text { accommodation }\end{array}$ & Paid carers & $\begin{array}{c}\text { Daughters/grand- } \\
\text { daughters }\end{array}$ \\
\hline 7 & Lives with daughter & None & Daughter and son-in-law \\
\hline 8 & $\begin{array}{c}\text { Lives in sheltered } \\
\text { accommodation }\end{array}$ & None & Daughter \\
\hline 10 & Lives alone & None & Daughter \\
\hline 11 & $\begin{array}{c}\text { Lives in sheltered } \\
\text { accommodation }\end{array}$ & None & Husband and family \\
\hline
\end{tabular}

\section{Ageless Innovation ${ }^{\circledR}$ Robot cat}

The companotic device used for this research was a commercially available companion cat (figure 1). It was originally developed by the US toy manufacturer Hasbro, but since 2018 is produced by a specialist companion pet company named 'Ageless Innovation'. 


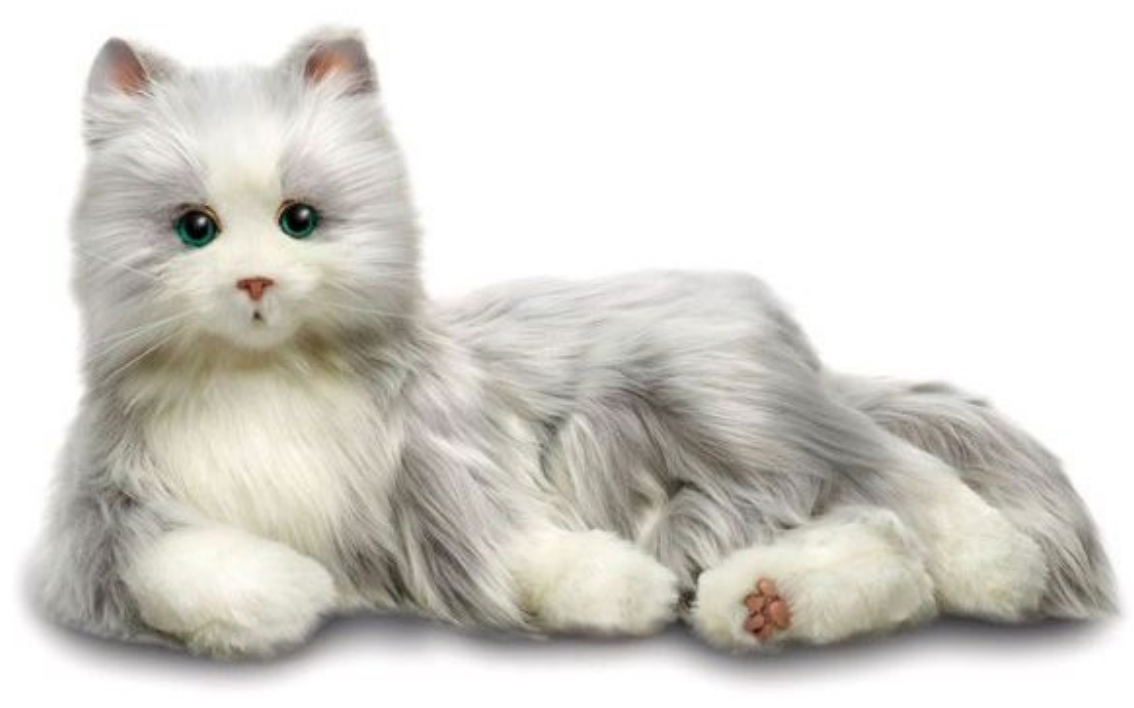

Figure 1: The 'Ageless Innovation' companion cat

This product is marketed specifically for older people, and "... with a focus on improving quality of life for aging loved ones, their families, and caregivers" ("Ageless Innovation", 2019). The cat vocalizes with meows and purrs in reaction to light and touch, via its on-board sensors. It moves its mouth, eyes, head and also rolls over, again in response to human interaction. Strictly speaking, it is not a robotic device, as in its off-the-shelf form, it is not programmable. However, it operates in two modes: mute or sound. In both modes, the cat's movements continue to function. It is battery-powered, and the researchers have tested that the replaceable battery life is long (months, not weeks).

A fundamental criterion for accessibility and inclusion, especially given the demographics for this user population, is affordability. Other companion robots are much more expensive, and this is one of the main reasons we selected this device for our research study, as at the time of writing it is priced in the region of $£ 100$ GBP. Although the cat is relatively simplistic in its operation, we postulated that its functionality would be enough for the purposes of this research, and for the engagement of our participants. This assumption was confirmed in preliminary pilot analysis.

\section{Results}

As previously explained, the results are presented as a case study bringing individual results together across the quintain. The reporting of the results is structured according to the four themes identified in the thematic analysis; Acceptance and rejection, Distraction, Communication and Connecting with the cat and connecting with others. .

\section{Theme: Acceptance and rejection}

This first theme brings together the discussions around acceptance of the cat, presenting the interpretation of the results supported by direct quotes from the 
participants discussing this. Interestingly, there was no guarantee when presenting the robot cat to a person with no diagnosis but with apparent symptoms of dementia, that it would be accepted. Asking screening questions, such as 'Do you like cats?' did not entirely predict the likelihood of the person engaging with the cat unless they strongly disliked cats, in which case rejection was immediate on this basis (participant one, male). People who did not dislike cats were more amenable to accepting it. However, there was also the possibility of an immediate dislike of the fact that the cat looked so realistic, which could possibly be attributed to the well-documented 'Uncanny Valley' phenomenon (Mori, 2012). This is discussed in more detail later in this paper. Even with the cat 'turned off', the rejection by one participant on the grounds of its "spooky" appearance meant that the cat had to be put away in its box and the box hidden out of sight. In this case the participant noted that she would much rather "stick to her teddies thank you" as they were "much more of a comfort" (participant two, female: research diary notes). Even though it was not possible to enrol this participant to the study, and no interview was able to be carried out, the data gleaned here were powerful, as the disgust registered on participant two's face, and the negative body language (turning away from the cat and eyeing it with distrust) demonstrated to the researcher that immediate rejection of the cat was possible on this basis. This had not been previously considered, but the reaction was so strong, that the researcher did not feel she could leave the cat with participant two to try, for fear of upsetting her.

Participant three also rejected the cat, asserting that she did not think it would help her. She lived independently, and had very mild dementia symptoms, as reported by her daughter. On the day of the first meeting, during which the research was explained, the cat shown, and an appointment made to return for interview, her daughter was present. There was no immediate rejection, and she was happy to "try it", but on returning on the appointed interview date, the participant met the researcher at her front door saying, "I don't think it will help me" (participant three: taken from research notes). On this basis, and because she said, "No, I've not switched it on", no interview was possible.

At this point, what seemed to be predictive of rejection of the cat therefore, was a dislike of cats, finding the cat 'spooky', and whether there was usually resistance to interventions or offers of support. Participant four's family asked the researcher not to mention the 'D word' (dementia) in their mum's earshot, as she did not accept the diagnosis. During the discussion, the family thought that there was a link between this and the acceptance of any interventions or help. Participant four's family noted how she did not want the cat, discussing:

"She rejected it, it never really worked for her. The daughter (Granddaughter of participant four) has a dog which she brings and she sits there and strokes it. That's why I thought it would work for her (Daughter four A). You've got to buy into it I think (Daughter four B)'”. It's interesting to know that it doesn't work for her. We brought it out, but there was not really a response to it (Daughter four A)".

This person rejected most interventions, and the family felt that they were unable always to "reach her" and didn't "know what to do to help her a lot of the time" (Daughter four A). The family had hoped the cat would help, but because of her 
inability to respond to it, following the initial interview, the family asked for it to be taken away.

Of the possible reasons for accepting the cat, those observed here were being a cat lover, and finding the cat 'cute' or 'pretty'.

\section{Theme: Distraction}

Some participants, 'enjoyed having something there' (participant five) whatever dementia symptoms they displayed. Although participant five knew that the cat was not real, she enjoyed its presence and its actions. While this lady did not want the cat on her lap, and preferred the cat not to 'meow' too much, she had it close to her on the chair and stroked it often during the interview. Her husband also was pleased, saying the cat was always by his wife and that she seemed to enjoy its "company" (husband of participant five).

Participant five noted:

"It's calmed me down a bit, yes. I used to get 'het up'. The purr helps calm me down a little bit”.

and her husband commented:

“... it's brought back memories, she is a cat person, yes, but the cat has helped her to calm down in general".

It was confirmed by participant five's body language - the cat was sitting next to her and she stroked it and laughed as it meowed and purred. She tended to zoomorphise it, saying, "It looked up at me. It just amuses me. I pick it up at any time". However, there was also some contradiction, in that the participant knew that it was not real. Although it had helped her to be calm in general, her husband was unsure whether it had made a difference to her anxiety at peak times. Her husband noted: "(She) misses the real cat - it used to come to her and put itself on her lap". The act of paying attention to the robot cat was a nice distraction, but it did not replace a real cat for this lady. Participant eight, however asked about feeding it and letting it out, and seemed to accept the researcher's response unconditionally when reminding her that it had batteries and would not need to be fed. She "put the cat to bed on the sofa at night" and said how much she loved it. So while she accepted it was not real, she still wanted to care for it and treat it as one would for a real cat, though unfortunately, the researchers were unable to follow up with a later interview, and it was not possible to determine whether this behaviour continued.

Participant eight's daughter asked for a cat for her mother as she felt it would help her. This lady had unpredictable behaviour, and her daughter thought the cat could be a distraction from that behaviour and might help to stabilise her moods. This lady accepted the cat immediately, initially knowing it was a robot cat as the researcher had demonstrated where to put the batteries, but she seemed to forget that straight away, stroked it and talked to it as though it were real. She was very responsive to the cat. It was unfortunate that this lady was admitted to hospital and therefore the short initial interview was the only one that was carried out. During this interview, other 
than discussing how much she liked the cat, it was not possible to determine the impact of the cat on this lady's behaviour, as it was very early stages in the process for her. Potentially, the planned later interview may have elicited further information regarding any changes in patterns of her behaviour.

\section{Theme: Communication}

For some participants, the cat became a subject of conversation between the participants and their families and carers.

Husband eleven said:

"Well, we can have a bit of fun with it when she's (the cat's) with us, especially with the carers. They think it's real, and then when it moves they jump!"

and he noted: "and the carers are interested in it, they talk to her about it too".

In this way, communication was stimulated, and families particularly noted this where communication had previously decreased. This appeared to be partly a function of the novelty of the cat, but was protracted, lasting at least three months (between the first and the second interviews). The impact on Family eleven was striking. This lady had quite severe dementia symptoms and had almost totally withdrawn from her husband, family and carers. She needed help with all aspects of care, including prompting to eat and to drink. She was displaying repetitive behaviour, calling out during the evenings, which fluctuated with periods of silence. Her family found it very difficult to reach her, and could not ascertain her wishes when asked simple questions, such as "would you like a drink?". Participant eleven was less withdrawn when the cat was beside her and would respond in crooning tones to the cat when it meowed and would focus on it when it moved. The cat was also "good when she's shouting". Granddaughter eleven said:

"I try to get Grandad to bring the cat out when Gran is shouting, to see if it will help. It's a bit worrying for me, because I can see Grandad getting really fed up and tired, especially in the evenings. I worry that Gran's shouting gets him down. Yes, the cat does help a bit, for a short time, but I think Gran's at such a stage that it's difficult for anyone or anything to reach her. It's funny though, that the cat reaches her where we can't always. You wouldn't think it would, would you?"

During her interview, participant six was happy, and would talk to the cat at intervals. The family, delighted with their mum and grandmother's calm, settled and happy demeanour, explained how good her communication had become since she had the cat, even noting some perceived improved memory:

"Cat: Meow

Participant six: (In response to the cat's meow - speaking to the cat) Hello, there's a good girl...

Interviewer: And she talks to you, doesn't she?

Participant six: Yeah. 
Granddaughter six: The whole family like her don't they (Grandma)? The girls came from (Country) and they seen her, haven't they? And they like her.

Daughter six: Yeah, they were here last week for a week.

Participant six: Yeah, it was lovely, wasn't it?

Daughter six: It was lovely. You see (to interviewer), she's remembered that, as well!

Interviewer: Is that unusual?

Daughter and Granddaughter six together: Yeah

Interviewer: Is it?

Daughter six: Definitely.

Participants, family and carers identified that conversations were stimulated as a response to the meow, purr, and movement of the cat, and that this promoted communication with family and others. This was an important result of the research.

\section{Theme: Connecting with the cat and connecting with others}

Some participants and families found that there was a real stimulation occurring that went beyond motivating conversation. One of the strongest reactions came from participant six, whose interview was the longest as her family were delighted with the increase in her engagement with them since having the cat. This lady had exhibited a recent deterioration of mood, functioning and communication. She had been referred to the researchers by the care staff in the supported living complex where she resided, and her family consented to their mum/grandma's participation in the study. On visiting, the lady was said to be really fond of cats but would be unable to care for a real cat. She loved a toy cat that was in the communal space in the complex, and often spent time petting it. This may well have been a predictor of the immediate and strongly positive reaction on first meeting the robot cat. As the cat was brought into the room, she held out her hands to the cat saying, "Where have you been?" addressing the cat, and took it into her arms and straight to her lap where she stroked it and spoke to it with affection.

The subsequent interview visit to participant six with her family present demonstrated a continuing strongly positive reaction to the cat. The most telling of the positive reactions came from Daughter six who, discussing the effect of the cat on her mother's wellbeing, said it had "given her a new lease of life" (Daughter six). Her granddaughter went further, stating that it had, "Given her a purpose" (Granddaughter six). When asked to discuss this further, her granddaughter was emphatic, saying, "Oh yeah", and her daughter said again, "Yeah, definitely. It's like as if she's got a purpose now". This is a result beyond that which might have been predicted. This lady had a much deeper emotional response to the robot cat than simply being calmed or being stimulated to converse with others. Further discussion during the interview elicited that this lady's clinical assessment prior to having the cat had led to advice that she may have to move to residential care. A later clinical assessment (after having had the cat for several weeks) had been undertaken, during which the clinician had noted a considerable improvement in her condition, and that there was no need to move to residential care and could stay in her current home. This delighted the family, and was, they felt, confirmation of the cat's impact on their mother's general wellbeing. The carers were able to confirm the positive impact of the cat (research notes) noting that she was more amenable to getting up in the morning and to sticking 
to mealtime routines than she had been, and they used the cat as prompts to get out of bed in the morning saying phrases such as "(The cat's name) is waiting for you". This was a prompt used to avoid resistive behaviour, and tended to work for participant six most of the time. One episode was upsetting for the family, when participant six was particularly unwell:

Granddaughter six: So we had to get the carers in, she was hallucinating, thinking she was in a taxi, in a hospital bed, and... just horrendous.

Interviewer: Terrible. (All murmur in agreement).

Granddaughter six: It was, it was, her mood changed instantly when she saw the cat.

Interviewer: Really?

D: Yeah, definitely.

Granddaughter six: We were like, "Thank you, (cat's name)!"

(All laugh)

Interviewer: So, it was like, she saw (cat's name), and her mood changed?

Granddaughter six: Yeah

Daughter six: Straight away.

Interviewer: Straight away?

Daughter six: Straight away.

Granddaughter six: You can't really describe that, unless you've seen it through your own eyes,

Daughter six: Yeah

Granddaughter six: because it was just like...

Interviewer: A switch?

Granddaughter six: Yeah

Daughter six: Yeah, definitely!

In contrast to this, connecting with the cat is shown differently for participant seven whose daughter found that "... she enjoys the cat's company" but liked it to be "turned off" as it made her anxious to hear it meow. Her daughter said, "I think it's because she's not sure what to do when it cries. She said, "she kept asking me if it was alright, so we turned it off'. In this case, it seemed to increase participant seven's anxiety, but she liked it to be close by her on the sofa at all times, and became very "attached to it". Her daughter noted "it's like an anchor for her" and when asked what she meant, she responded:

"Well - it's almost like she's more with me somehow. I don't know whether it's because of the cat, I don't know" (participant's emphasis).

Likewise, participant ten's daughter found her mum more settled in the evenings "lovely and settled" because she "has someone with her all the time". This pleased daughter ten:

"Well she usually rings me all the time in the evenings. Since she has had the cat it has been less of a bother. She wanted to know where (cat's name) was, because she always used to let him out and then wander the streets looking for him. That's why I wanted a ginger one because (cat's name) was ginger, and this one is so like him!" 
The impact of the cat on daughter ten was obvious and very moving, as her mother tended to be quite quiet during the interview. The impact on family ten mirrors the impact of the cat on family six, who were so grateful that the cat had made such a difference to participant six's communication and ability to take part in family gatherings and conversations. 


\section{Discussion}

In the Results section, four themes have been presented, which are now synthesized into two overarching themes to facilitate the discussion below. The first of these is related to the effect of the cat on the person's mood or behaviour, and synthesizing themes Communication and Distraction, and the second is related to the interaction with the robot cat itself, bringing together themes Acceptance and rejection and Connecting.

\section{The effect of the cat on mood and behaviour (Communication and Distraction)}

The benefits of the robot cat were clear in terms of improving communication and providing a distraction from repetitive behaviour, and although this was a small-scale study, where they were accepted, the cats provided positive benefits for the participants and their families. Similar benefits for people with mental health problems have been found with companion pets, though research shows that there are practical and emotional burdens associated with pet ownership (Brooks et al., 2018). In our study, one daughter in particular discussed the difficulties her mother had experienced with worrying where her pet cat was at night, and how the robot cat had replaced the real cat very well. Some surprisingly strong changes to the participants were noted in terms of improvements and stability in behaviour, but further research will need to be undertaken in order to determine whether this was a sustained change over a longer period of time. Stability of mood and interruption of repetitive behaviour has been noted and this was of particular benefit to the family carers.

Carers of people living with dementia may become stressed (Svendsboe et al., 2018) and their quality of life can be adversely affected (Farina et al, 2017). Evidenced by the reaction of some participant's families, the robot cat appears to have had a positive effect on the carers' wellbeing, through its ability to modify mood and its calming effect. Though this was variable, the most positive benefits appear to have occurred for carers of those participants experiencing moderate to severe dementia symptoms, distracting from repetitive symptoms and providing an anchor to reality.

The benefits of the cat were also related to stimulating conversation between the family and their loved one. It appeared to bring the family together and to stimulate conversation, where it had been previously difficult. The strongest reaction again came from those participants who were experiencing moderate to severe symptoms.

\section{Interaction with the cat (Acceptance and rejection, and connecting)}

Where participants accepted the cat, many of the participants responded to the it as though it were real, stroking it and talking to it in response to its movements, purrs and meows. There was evidence of zoomorphism in that they spoke to the cat, thereby demonstrating a degree of suspension of disbelief that the cat was not alive. Further, an emotional connection seemed to be made with the cat, as the participants appeared to talk lovingly to the cat, sometimes even when conversations could not be held with other people.

What became clear in our interviews and observations were that the cat's level of interaction had a variable effect on the participants. Some accepted its repetitive 
meowing, others didn't. Also, the cat's tendency to roll over on its back occasionally caused distress for some, especially when this action was perceived as the cat falling from the participant's arms or lap. In some cases, it was also important that the cat's vocalisation sounds could be 'turned off'. The meow appeared to some participants as the cat asking for something, and where the participant was unable to respond to the perceived need, some distress could be caused.

The cat's appearance also had a variable affect. This might relate to the phenomenon of the 'Uncanny Valley', first proposed by Mori in the 1970s (Mori, 2012). This phenomenon considers how a person might react emotionally to objects as they increasingly resemble a human being. The 'valley' effect occurs when the object is very similar to a living human, but not identical. Mori hypothesized that there would be an emotional disturbance at that point, using a 'zombie' and a corpse as examples (figure 2).

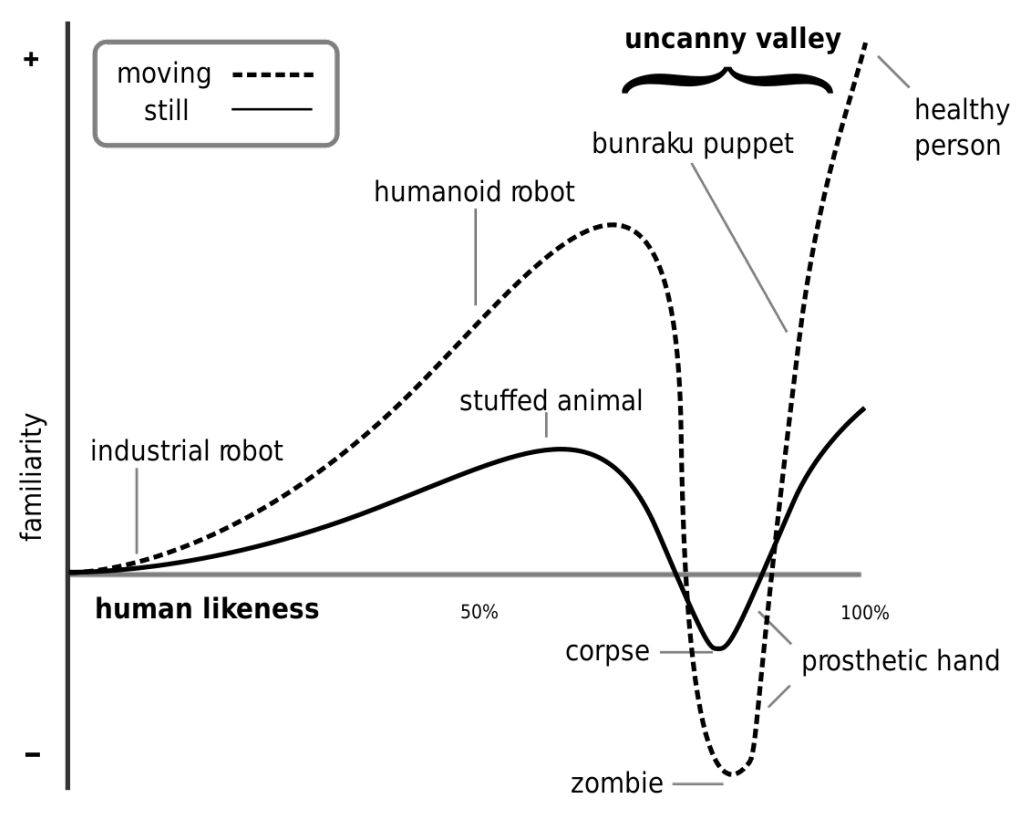

Figure 2: The Uncanny Valley (Mori, 2012).

Whilst the Uncanny Valley focuses specifically on humans, it is clear that such a phenomenon can apply to other living beings in a zoomorphic as opposed to anthropomorphic scenario, and this has indeed been considered by researchers of social robotics (Dalibard, Magnenat-Talmann \& Thalmann, 2012).

Although the Uncanny Valley applies specifically to the visual senses, there is no reason why this could not be extended, and this has been proposed in the aural senses by Grimshaw (2009) in the context of computer games sounds. To our knowledge, it has not been researched in the domain of robotics, and this is an area in which we are planning to undertake further experimental studies, particularly in the light of some participants in our study preferring the cat with its sounds deactivated. 


\section{Conclusions}

This research study considered the proposition that various factors influence the impact of a robot pet on people with dementia and their carers, including acceptability of the pet and their acceptance of dementia and its symptoms.

In terms of acceptability of the cat, we experienced a wide effect from our participants, from total rejection on sight, to 'love at first sight'. The functions of vocalization and movement also had a variable effect, and this highlights the need for more nuanced personalization. For example, a noisy cat caused one participant a degree of anxiety. Generally, wider research with robot companion pets in care home settings does suggest positive benefits (Chang, Šabanović \& Huber, 2013; Kachouie, Sedighadeli, Khosla \& Chu, 2014), although there is a wish for the robots to be more technologically advanced in order to adapt their use for the needs of individual users (Jung, van der Leij \& Kelders, 2017). Of course, this has cost implications, and the authors of this paper are currently researching affordable ways to enhance the 'Ageless Innovation' cat to support full robotic functionality. Future robotics in this domain might consider the role that artificial intelligence may offer, although this discussion is controversial and outside the domain of this paper. However, readers might find Dautenhahn's (2007) comprehensive discourse on socially intelligent robots to be of interest.

The results of this study show that for individuals living at home, where assistance is accepted from others and where the robot cat is accepted, there are positive benefits. The cat encouraged communication with others, and often became a talking point within the wider family. Where the participant enjoyed the sound and movement, the stimulation provided by the cat's meow and motion encouraged a connection and stroking of the cat that was often calming where dementia symptoms were distressing. In one particular case, there was even an improvement in symptoms over a period of time, helping one lady to stay in her own home for longer. Table 3 summarises the key findings of this study. It is encouraging that the number of positive effects resulting from this small study far outweigh the negative. 
Table 3. Summary of key findings

\begin{tabular}{|c|c|c|}
\hline Themes & Key findings & $\begin{array}{l}\text { Positive }(+) / \\
\text { negative }(-) \\
\text { effect }\end{array}$ \\
\hline $\begin{array}{l}\text { The effect of the } \\
\text { cat on mood and } \\
\text { behaviour } \\
\text { (Communication) }\end{array}$ & $\begin{array}{l}\text { Can stimulate communication for individuals, family and } \\
\text { carers alike. } \\
\text { People can become less withdrawn. } \\
\text { The cat's robotic behaviour can act as a communication } \\
\text { theme. } \\
\text { Can improve carers' wellbeing. } \\
\text { Can improve stability of behaviour. }\end{array}$ & $\begin{array}{l}+ \\
+ \\
+ \\
+ \\
+ \\
+\end{array}$ \\
\hline $\begin{array}{l}\text { The effect of the } \\
\text { cat on mood and } \\
\text { behaviour } \\
\text { (Distraction) }\end{array}$ & $\begin{array}{l}\text { Knowing the cat isn't real is not always a problem. } \\
\text { Can help people keep calm and reduce anxiety/moods. } \\
\text { Zoomorphic properties can be positive (e.g. distraction } \\
\text { through stroking, listening to purring) ... } \\
\ldots \text { or negative (e.g. people attempting to care for the cat } \\
\text { as if it was real and getting distressed). }\end{array}$ & $\begin{array}{l}+ \\
+ \\
+ \\
-\end{array}$ \\
\hline $\begin{array}{l}\text { Interaction with } \\
\text { the cat } \\
\text { (Acceptance and } \\
\text { rejection) }\end{array}$ & $\begin{array}{l}\text { Rejection more likely in early stages. } \\
\text { Acceptance more likely by people who already like cats. } \\
\text { 'Uncanny Valley' effect may adversely affect } \\
\text { acceptance. } \\
\text { People resistant to change less likely to accept. }\end{array}$ & $\begin{array}{c}- \\
+/- \\
- \\
-\end{array}$ \\
\hline $\begin{array}{l}\text { Interaction with } \\
\text { the cat } \\
\text { (Connecting) }\end{array}$ & $\begin{array}{l}\text { Can stimulate positive emotions such as affection. } \\
\text { Can contribute to reinforcing routine and adherence. } \\
\text { Can cause anxiety when calling out (meowing). } \\
\text { Can help settle and act as company. }\end{array}$ & $\begin{array}{l}+ \\
+ \\
- \\
+\end{array}$ \\
\hline
\end{tabular}

Although the study reported in this paper is of small scale, it has offered a unique and important insight into the appropriateness for introducing companion robot pets into an individual's home environment. Future studies might consider larger-scale randomized control models of research with formal diagnoses of stage of dementia, but the very nature of the research domain does not make this an easy approach, as is demonstrated in published systematic reviews of social robots in elderly care (Kachouie et al., 2014; Broekens, Heerink \& Rosendal, 2009). 


\section{Declaration of Conflicts of Interest}

None

\section{Funding}

This research was undertaken without funding, but was performed as part of the employment of the authors. 


\section{References}

Abdi, J., Al-Hindawi, A., Ng, T., \& Vizcaychipi, M. P. (2018). Scoping review on the use of socially assistive robot technology in elderly care. BMJ Open, 8:e018815. doi:10.1136/bmjopen-2017-018815 Ageless Innovation: Our Story (2019, July 30). Retrieved from https://joyforall.com/pages/our-story Bernabei, V., De Ronchi, D., La Ferla, T., Moretti, F., Tonelli, L., Ferrari, B., ... \& Atti, A. R. (2013). Animal-assisted interventions for elderly patients affected by dementia or psychiatric disorders: a review. Journal of psychiatric research, 47(6), 762-773.

Broekens, J., Heerink, M., \& Rosendal, H. (2009). Assistive social robots in elderly care: a review. Gerontechnology, 8(2), 94-103.

Brooks, H.L., Rushton K., Lovell, K., Bee, P., Walker, L., Grant, L., \& Rogers, A. (2018). The power of support from companion animals for people living with mental health problems: a systematic review and narrative synthesis of the evidence. BMC Psychiatry, 18(31), 1-12.

Burton A. (2013). Dolphins, dogs, and robot seals for the treatment of neurological disease. The Lancet Neurology, 12(9), 851-852.

Chang, W-L., Šabanović, S., \& Huber, L. (2013). Use of seal-like robot PARO in sensory group therapy for older adults with dementia. In Proceedings of the 8th ACM/IEEE International Conference on Human-Robot Interaction (HRI '13), Tokyo, Japan, March 2013 (pp. 101-102), IEEE Press.

Cherniak, E.P., \& Cherniak, A.R. (2014). The benefits of pets and animal assisted therapy to the health of older individuals. Current gerontology and Geriatrics Research. doi:10.1155/2014/623203 Chmiliar, L. (2010). Multiple-Case designs. In A.J. Mills, G. Durepos \& E. Wiebe (Eds.), Encyclopedia of Case Study Research. Thousand Oaks, CA: SAGE publications, Inc.

Cho, K., Kwon, J. \& Shin, D. (2009). Trends of cognitive robot-based intervention for autism spectrum disorder. Journal of Korean Association for Person with Autism, 9(2), 45-60.

Dalibard, S., Magnenat-Talmann, N., \& Thalmann, D. (2012). Anthropomorphism of Artificial Agents: A Comparative Survey of Expressive Design and Motion of Virtual Characters and Social Robots. Workshop on Autonomous Social Robots and Virtual Humans at the $25^{\text {th }}$ Annual Conference on Computer Animation and Social Agents (CASA 2012), May 2012, Singapore, Singapore.

Dautenhahn, K. (2007). Socially intelligent robots: dimensions of human-robot interaction. Philos Trans R Soc Lond B Biol Sci., 2007 Apr 29, 362(1480), 679-704.

Denzin, N.K., \& Guba, Y.S. (1998) Strategies of Qualitative Enquiry. Thousand Oaks, CA: Sage Publications

Farina, N., Page, T.E., Daley, S., Brown, A., Bowling, A., Basset, T., Livingston, G., Knapp, M., Murray, J., \& Banergee, S. (2017). Factors associated with the quality of life of family carers of people with dementia: A systematic review, Alzheimer's \& Dementia: The Journal of the Alzheimer's Association, 13(5), 572-581.

Feil-Seifer, D., \& Mataric, M.J. (2008). B3IA: a control architecture for autonomous robot-assisted behavior intervention for children with autism spectrum disorders. In Proceedings of the 17th IEEE International Symposium of Robot Human Interaction and Communication, Aug. 1-3, Munich, Germany.

Glaw, X., Inder, K., Kable, A., \& Hazelton, M. (2017). Visual Methodologies in Qualitative Research: Autophotography and Photo Elicitation Applied to Mental Health Research. International Journal of Qualitative Methods, 16, 1-8.

Gustafsson, C., Svanberg, C., \& Muellersdorf, M. (2015). Using a Robotic Cat in Dementia Care: A Pilot Study, Journal of Gerontological Nursing, 41(10), 46-56.

Grimshaw, M.N. (2009) The audio Uncanny Valley: Sound, fear and the horror game. in Proceedings of Audio Mostly 2009, Glasgow, United Kingdom, February 2009 (pp. 21-26).

Heidegger, M. (1962) Being and Time (Transl. Macquarrie and Robinson) Oxford: Blackwell Ltd. Joransen, N., Pedersen, I., Rokstad, A.M.M., \& Ihlebaek, C. (2015). Effects on symptoms of agitation and depression in persons with dementia participating in robot-assisted activity: a cluster-randomized controlled trial. Journal of American Medical Directors Association, 16(10), 867-73.

Jung, M.M., van der Leij, L., \& Kelders, S.M. (2017). An Exploration of the Benefits of an Animallike Robot Companion with More Advanced Touch Interaction Capabilities for Dementia Care. Frontiers in ICT, 26. Retrieved from: https://doi.org/10.3389/fict.2017.00016

Kachouie, R., Sedighadeli, S., Khosla, R., \& Chu, M-T. (2014). Socially Assistive Robots in Elderly Care: A Mixed-Method Systematic Literature Review. International Journal of Human-Computer Interaction, 30(5), 369-393. doi: 10.1080/10447318.2013.873278

Kidd, C. D., Taggart, W., \& Turkle, S. (2006). A sociable robot to encourage social interaction among the elderly. In Proceedings 2006 IEEE International Conference on Robotics and Automation, 
ICRA 2006 (pp. 3972-3976).

Kim, K.H., Lee, H.S, Jang, S.J., \& Ku, H.J. (2010). The Reaction of Children Labeled with Autism through Interactions with Robot. Journal of emotional and behavioral disorders, 26(1), 331-353.

Libin, A., \& Cohen-Mansfield, J. (2004). Therapeutic robocat for nursing home residents with dementia: Preliminary inquiry. American Journal of Alzheimer s Disease and Other

Dementias, 19(2), 111-116.

Lincoln, Y.S., \& Guba, E.G. (1985) Naturalistic Inquiry Newbury Park: CA: Sage Publications McNicholas, J., Gilbey, A., Rennie, A., Ahmedzai, S., Dono, J. A., \& Ormerod, E. (2005). Pet ownership and human health: a brief review of evidence and issues. BMJ, 331(7527), 1252-1254. Mendes, A. (2016). Animal-assisted therapy for people living with dementia. Nursing \& Residential Care, 18(4), 214-216.

Mengoni, S.E., Irvine, K., Thakur, D., Barton, G., Dautenhahn, K., Guldberg, K., Robins, B., Wellsted, D., \& Sharma, S. (2017). Feasibility study of a randomised controlled trial to investigate the effectiveness of using a humanoid robot to improve the social skills of children with autism spectrum disorder (Kaspar RCT): a study protocol. BMJ Open, 7:e017376. doi: 10.1136/bmjopen2017-017376

Mori, M. (2012). The uncanny valley (K.F. MacDorman \& N. Kageki, Trans.). IEEE Robotics and Automation, 19 (2): 98-100.

Moyle, W., Beattie, E., Draper, B., Shum, D., Thalib, L., Jones, C.O., Dwyer, S., \& Mervin, C.

(2015). Effect of an interactive therapeutic robotic animal on engagement, mood states, agitation and psychotropic drug use in people with dementia: a cluster-randomised controlled trial protocol. $B M J$ Open, 5(8): e009097. doi: 10.1136/bmjopen-2015-009097

Moyle, W., Cooke, M., Beattie, E., Jones, C., Klein, B., Cook, G., \& Gray, C. (2013). Exploring the Effect of Companion Robots on Emotional Expression in Older Adults with Dementia: A Pilot Randomized Controlled Trial. Journal of Gerontological Nursing, 39(5), 46-53.

Murray, L. \& Nash, M. (2017). The Challenges of Participant Photography: A Critical Reflection on Methodology and Ethics in Two Cultural Contexts, Qualitative Health Research, 27(6), 923-937.

Nalin, M., Baroni, I., Sanna, A., \& Pozzi, C. (2012). Robotic companion for diabetic children: emotional and educational support to diabetic children, through an interactive robot. In Proceedings of the 11th International Conference on Interaction Design and Children (IDC '12), New York, NY, USA (pp. 260-263), ACM.

Peacock, J.L. (2001) The Anthropological Lens: Harsh Light, Soft Focus $2^{\text {nd }}$ ed. Cambridge: Cambridge University Press.

Picking, R. \& Pike, J. (2017). Exploring the effects of interaction with a robot cat for dementia sufferers and their carers. In Proceedings of 7 th International Conference on Internet Technologies and Applications (ITA 17), Wrexham, UK (pp. 209-10).

Rabbitt, S.M., Kazdin, A.E., \& Scasellati, B. (2014). Integrating socially assistive robotics into mental healthcare interventions: Applications and recommendations for expanded use, Clinical Psychology Review, 35, 35-46.

Robinson, H., Macdonald, B., Kerse, N., \& Broadbent, E. (2013). The psychosocial effects of a companion robot: a randomized controlled trial. Journal of American Med Dir Assoc., 14(9), 661667.

Shibata, T. (2012). Therapeutic Seal Robot as Biofeedback Medical Device: Qualitative and Quantitative Evaluations of Robot Therapy in Dementia Care. Proceedings of IEEE, 100(8), $2527-$ 2538.

Sparrow, R., \& Sparrow, L. (2006). In the hands of machines? The future of aged care. Minds and Machines, 16, 141-161.

Stake, R.E. (2005). Qualitative case studies. In N. K. Denzin \& Y. S. Lincoln (Eds.), The Sage handbook of qualitative research (3rd ed., 443-466). Thousand Oaks, CA: Sage.

Stake, R.E. (2006). Multiple Case Study Analysis. New York, NY: Guilford Publications.

Svendsboe, E.J., Testad, I., Terum, T., Jörg, A., Corbett, A., Aarsland, D., \& Rongve, A. (2018). Patterns of carer distress over time in mild dementia. International Journal of Geriatric Psychiatry. Retrieved from https://doi.org/10.1002/gps.4882

Tanaka, M., Ishii, A., Yamano, E., Ogikubo, H., Okazaki, M., Kamimura, K., Konishi, Y., Emoto, S., \& Watanabe, Y. (2012). Effect of a human-type communication robot on cognitive function in elderly women living alone. Medical Science Monitor, 18(9):CR550-7.

Wada, K., \& Shibata, T. (2007). Social effects of robot therapy in a care house - Change of social network of the residents for two months. In Proceedings - IEEE International Conference on Robotics and Automation, Japan, 23 (pp. 1250-1255), IEEE.

Winner, S.F. (2014). Positive effect of pets on memory-impaired residents at Silverado communities. 
Working with older people, 18(3), 134-14.

Yazan, B. (2015). Three Approaches to Case Study Methods in Education: Yin, Merriam, and Stake. The Qualitative Report, 20(2), 134-152. Retrieved from https://nsuworks.nova.edu/tqr/vol20/iss2/12 
Appendix A: Example photographs taken by participants' carers used for photo elicitation
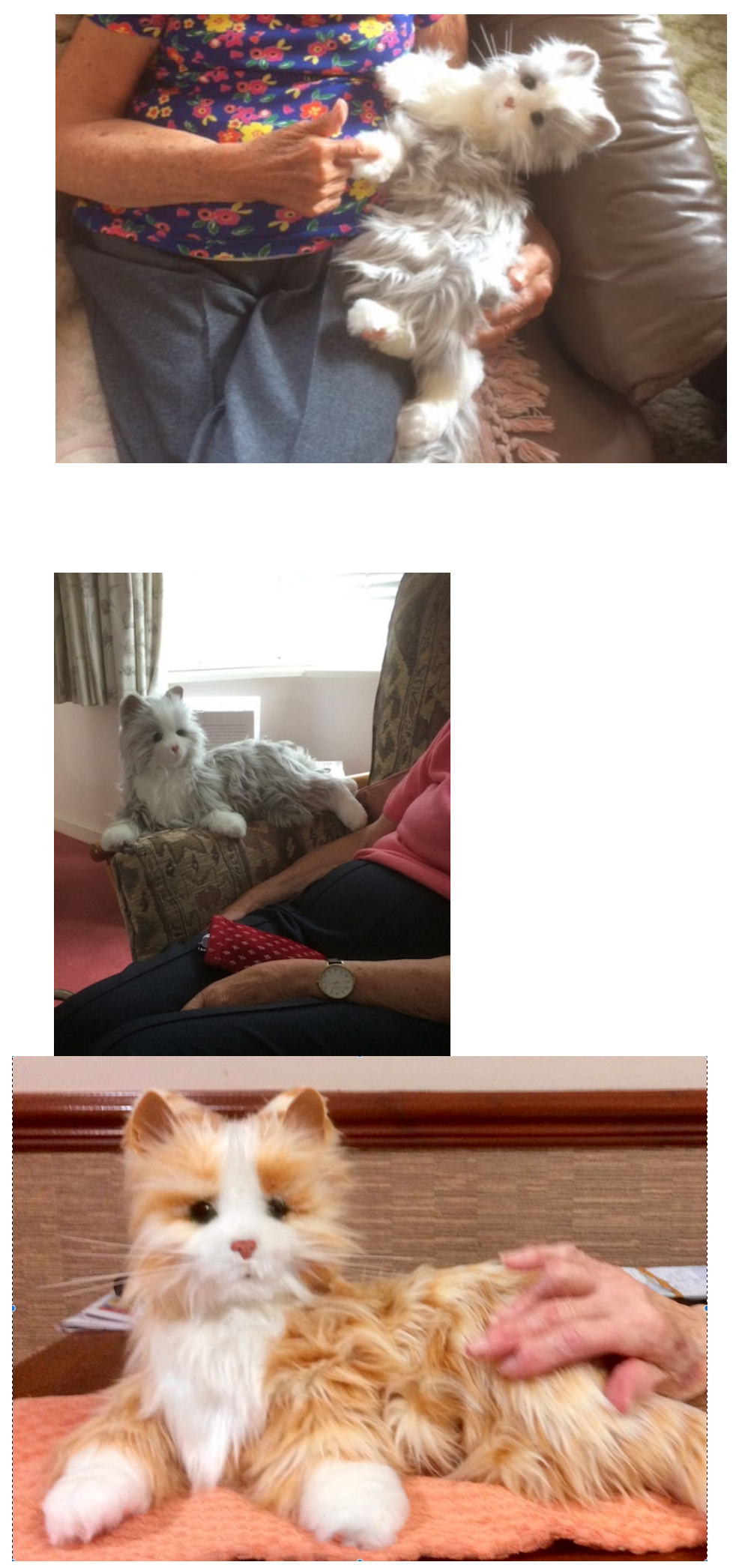